\title{
Adult growth hormone treatment reduces hypertension and obesity induced by an adverse prenatal environment
}

\author{
M H Vickers, B A Ikenasio and B H Breier \\ The Liggins Institute for Medical Research, Faculty of Medical and Health Sciences, University of Auckland, Private Bag 92019, Auckland, New Zealand \\ (Requests for offprints should be addressed to M H Vickers; Email: m.vickers@auckland.ac.nz)
}

\begin{abstract}
The discovery of a link between an adverse in utero environment and the propensity to develop metabolic and cardiovascular disease in adult life is one of the most important advances in epidemiological research of recent years. Increasing experimental evidence suggests that alterations in the fetal environment may have long-term consequences for the development of metabolic disorders in adult life. This process has been termed 'fetal programming' and we have shown that undernutrition of the mother during gestation leads to development of the metabolic syndrome $\mathrm{X}$ during adult life. Striking metabolic similarities exist between syndrome $\mathrm{X}$ and untreated GH deficiency (GHD). In the present study we have investigated the effects of $\mathrm{GH}$ treatment on blood pressure and metabolic parameters. Virgin Wistar rats (age $75 \pm 5$ days, $n=20$ per group) were time-mated and randomly assigned to receive food either ad libitum (AD) or 30\% of
\end{abstract}

AD intake (UN) throughout pregnancy. At weaning, male offspring were assigned to one of two diets (control or hypercaloric $(30 \%$ fat $))$. Systolic blood pressure was measured at day 100 and following twice daily treatment with recombinant bovine $\mathrm{GH}$ for 21 days. GH treatment increased body weights in all treated animals but significantly reduced retroperitoneal and gonadal fat pad weights. Following GH treatment, systolic blood pressure was markedly decreased in all UN offspring. Salinetreated animals showed no change in systolic blood pressure over the treatment period. GH treatment increased heart-to-body weight ratio in all GH-treated animals. Our data demonstrated that GH treatment reduces hypertension and improves cardiovascular function in animals exposed to adverse environmental conditions during fetal or postnatal life.

Journal of Endocrinology (2002) 175, 615-623

\section{Introduction}

There is now increasing evidence that metabolic and cardiovascular disorders which manifest in adult life have their roots before birth. This concept of fetal programming is based on epidemiological and experimental observations of close associations between an adverse intrauterine environment and the later onset of adult metabolic and cardiovascular disorders (Barker 1995, Jackson et al. 1996, Reynolds \& Phillips 1998, Godfrey \& Barker 2000).

We have developed an animal model of fetal programming by maternal undernutrition throughout gestation, generating a nutrient-deprived intrauterine environment that results in fetal growth retardation and postnatal growth failure, and leads to changes in allometric growth patterns and endocrine parameters of the somatotrophic axis (Woodall et al. 1996). Our model closely resembles the clinical and metabolic abnormalities seen in humans born at low birth weight and, furthermore, displays the phenotype of syndrome X (Reaven 1993, Smith et al. 1999). Offspring develop profound hyperphagia, obesity, hypertension, hyperinsulinaemia and hyperleptinaemia during adult life and postnatal hypercaloric nutrition amplifies the metabolic and cardiovascular abnormalities induced by fetal programming (Vickers et al. 2000).

Although the notion that growth hormone $(\mathrm{GH})$ is critical for normal growth, maintenance of skeletal muscle mass and metabolic homeostasis is well accepted, increasing attention has recently been directed towards the specific influences of $\mathrm{GH}$ on cardiac structure and function (Cittadini et al. 1996). There is now increasing evidence implicating $\mathrm{GH}$ in the cascade of events that regulates heart development and cardiac function (Sacca et al. 1994, Sacca \& Fazio 1996). For example, recent studies have shown improvements in diastolic blood pressure following GH therapy in hypopituitary adults (Johannsson et al. 1997, Bengtsson et al. 1999, Monson et al. 2000) and in GH-deficient (GHD) children (Sas et al. 2000). Although the precise mechanisms remain unknown, they may relate to changes in peripheral vascular resistance as proposed by others (Sacca et al. 1994, Bengtsson et al. 1999). This may be a direct result of reduced abdominal obesity via the lipolytic action of GH (Caidahl et al. 1994) or mediated by the action of insulin-like growth factor-I (IGF-I) on the 
vascular wall (Reaven et al. 1996) and increased nitric oxide synthesis (Bengtsson et al. 1999).

Striking similarities exist between syndrome $\mathrm{X}$ and untreated GHD in adults (Bengtsson 1993, Johannsson et al. 1997). Common to both these syndromes are abdominal/visceral obesity, insulin resistance and hypertension. The present study has investigated the response in blood pressure and metabolic parameters to $\mathrm{GH}$ treatment in adult life in offspring which experienced reduced substrate supply during fetal development alone or in combination with postnatal hypercaloric nutrition. The aim of the present study was to establish whether $\mathrm{GH}$ therapy can alleviate hypertension caused by an adverse fetal environment and/or postnatal diet-induced obesity.

\section{Materials and Methods}

\section{Animal model}

Virgin Wistar rats (age $75 \pm 5$ days, $n=15$ per group) were time-mated using a rat oestrous cycle monitor to assess the stage of oestrous of the animals prior to introducing the male. After confirmation of mating, rats were housed individually in standard rat cages containing wood shavings as bedding and free access to water. All rats were kept in the same room with a constant temperature maintained at $25{ }^{\circ} \mathrm{C}$ and a $12-\mathrm{h}$ light:12-h darkness cycle. Animals were assigned to one of two nutritional groups: group 1, standard diet available ad libitum (AD) throughout pregnancy and group 2, undernutrition (30\% of ad libitum intake (UN)) of a standard diet throughout gestation. Food intake and maternal weights were recorded daily until birth. After birth, pups were weighed and litter size was recorded. Pups from UN mothers were cross-fostered onto dams which received AD feeding throughout pregnancy. Litter size was adjusted to eight pups per litter to assure adequate and standardised nutrition until weaning. After weaning, male offspring from the two groups of dams, (a) AD offspring and (b) offspring from UN mothers, were divided into two balanced postnatal nutritional groups to be fed either a standard diet (total digestible energy $2959 \mathrm{kcal} / \mathrm{kg}$, protein $19.4 \%$, fat $5 \%$, fat/energy ratio $15 \cdot 21 \%$, protein/energy ratio $26 \cdot 23$ ) or a hypercaloric diet (total digestible energy $4846 \mathrm{kcal} / \mathrm{kg}$, protein $31 \cdot 8 \%$, fat $30 \%$, fat/energy ratio $55 \cdot 72 \%$, protein/ energy ratio $26 \cdot 25 \%$ ). The mineral and vitamin content in the two diets were identical and in accordance with the requirements for standard rat diets. The fat content of the hypercaloric diet is typical of that seen in many Western diets. Weights and food intake of all offspring were measured daily for the first 2 weeks then every second day. At day 100, systolic blood pressure (SBP) measurements were recorded using tail cuff plethysmography. Rats were then weight-matched and received either recombinant bovine GH (batch no. PR003, a gift from Dr W Baumbach, American Cyanamid Co., Princeton, NJ,
USA) at a dose of $10 \mu \mathrm{g} / \mathrm{g}$ per day or saline by twice daily subcutaneous injection $(0800 \mathrm{~h}$ and $1700 \mathrm{~h})$. On the day prior to death, a repeated SBP was recorded. Rats were then fasted overnight and killed by halothane anaesthesia followed by decapitation. Blood was collected into heparinised vacutainers and stored on ice until centrifugation and removal of supernatant for analysis. All animal work was approved by the Animal Ethics Committee of the University of Auckland.

\section{Blood pressure measurements}

SBP was recorded by tail cuff plethysmography (blood pressure analyser IITC; Life Science, Woodland Hills, CA, USA) as described previously (Vickers et al. 2001b). Rats were restrained in a clear plastic tube in a pre-warmed room $\left(25-28^{\circ} \mathrm{C}\right)$. After the rats had acclimatised (10$15 \mathrm{~min}$ ) the cuff was placed on the tail and inflated to $240 \mathrm{mmHg}$. Pulses were recorded during deflation at a rate of $3 \mathrm{mmHg} / \mathrm{s}$ and reappearance of a pulse was used to determine SBP. A minimum of three clear SBP recordings were taken per animal and the coefficient of variation for repeated measurements was $<5 \%$.

\section{Endocrine analyses}

IGF-I in rat blood plasma was measured using an IGF-binding protein-blocked radioimmunoassay (RIA) described previously (Vickers et al. 2001b). The half maximally effective dose (ED-50) was $0.1 \mathrm{ng} /$ tube and the intra- and interassay coefficients of variation were $<5 \%$ and $<10 \%$ respectively. Rat insulin was measured by an in-house RIA as described previously (Lewis et al. 1999). The ED-50 was $0.5 \mathrm{ng} / \mathrm{ml}$ and the intra-assay coefficient of variation was $<5 \%$ (all samples measured within a single assay). Leptin in rat plasma was measured by in-house RIA as described previously (Vickers et al. 2000). The ED-50 was $0.37 \mathrm{ng} / \mathrm{ml}$ and the intra-assay coefficient of variation was $<5 \%$ (all samples measured within a single assay).

\section{Blood biochemistry}

Fasting plasma glucose concentrations from samples taken at the time of death were measured using a YSI Glucose Analyzer (Model 2300; Yellow Springs Instrument Co., Yellow Springs, OH, USA). All other plasma analytes were measured by a BM/Hitachi 737 analyser by Auckland Healthcare Laboratory Services. Blood haematocrit was measured immediately after death on trunk blood collected into capillary tubes.

\section{Statistical analyses}

Statistical analyses were carried out using SigmaStat (Jandel Scientific, San Rafael, CA, USA) and StatView (SAS Institute Inc.) statistical packages. Differences 
between groups were determined by two-way (pre-GH treatment) or three-way (post-GH treatment) factorial ANOVA followed by Bonferonni post-hoc analysis and data are shown as means \pm S.E.M. Statistical significance was assumed at the $P<0.05$ level. The ANOVA effects are defined as follows: offspring of UN mothers 'programming effect'; postnatal hypercaloric nutrition 'diet effect'; GH treatment 'GH treatment effect'.

\section{Results}

\section{Maternal and fetal weights}

There was a marked reduction in maternal body weights in the UN group until day 15 of gestation. From day 15 of gestation, the UN dams gained weight and had achieved pre-mating weights by the time of parturition. Gestation was increased by 1 day in the UN dams. Litter size was not significantly different between the two groups (AD $11 \cdot 7 \pm 1.93$, UN $11.2 \pm 2.03$ ). Maternal undernutrition resulted in fetal growth retardation reflected by significantly decreased body weight at parturition in offspring from UN dams (AD 6.08 $\pm 0.03 \mathrm{~g}$, UN $4.04 \pm 0.02 \mathrm{~g}$, $P<0 \cdot 0001$ ). Body lengths (nose-anus) were markedly reduced in UN offspring at birth (AD $44.4 \pm 0.11 \mathrm{~mm}$, UN $38.8 \pm 0.16 \mathrm{~mm})$. From parturition until weaning at day 22 , neonatal weights remained significantly lower in UN offspring $(P<0 \cdot 001)$.

\section{Postnatal growth prior to and following GH treatment}

Hypercaloric nutrition resulted in a significant increase in body weight in both AD and UN animals. Total body weights for each diet remained significantly lower in UN animals compared with $\mathrm{AD}$ animals for the remainder of the study (Fig. 1). UN animals fed hypercaloric nutrition showed apparent catch-up growth and by postnatal day 100 had reached the same weight as AD animals fed the control diet. Body lengths (nose-anus) were significantly shorter in UN animals compared with AD animals on both diets. GH treatment resulted in marked body weight gain and increased body length in all treated animals (Table 1). There was no significant difference in weight gain response to $\mathrm{GH}$ treatment between $\mathrm{AD}$ and $\mathrm{UN}$ animals (Fig. 2).

\section{Systolic blood pressure}

Prior to the onset of $\mathrm{GH}$ treatment, UN offspring had significantly $(P<0 \cdot 001)$ elevated SBP compared with $\mathrm{AD}$ offspring. SBP was further significantly $(P<0 \cdot 001)$ elevated by postnatal exposure to hypercaloric nutrition (AD control $114 \cdot 3 \pm 3 \cdot 23 \mathrm{mmHg}$, UN control 136.3 \pm $3.52 \mathrm{mmHg}$, AD hypercaloric $143.6 \pm 3.37 \mathrm{mmHg}$, UN hypercaloric $150 \cdot 9 \pm 3 \cdot 15 \mathrm{mmHg}$ ). Treatment with GH for 21 days significantly reduced SBP $(P<0 \cdot 05)$ with the

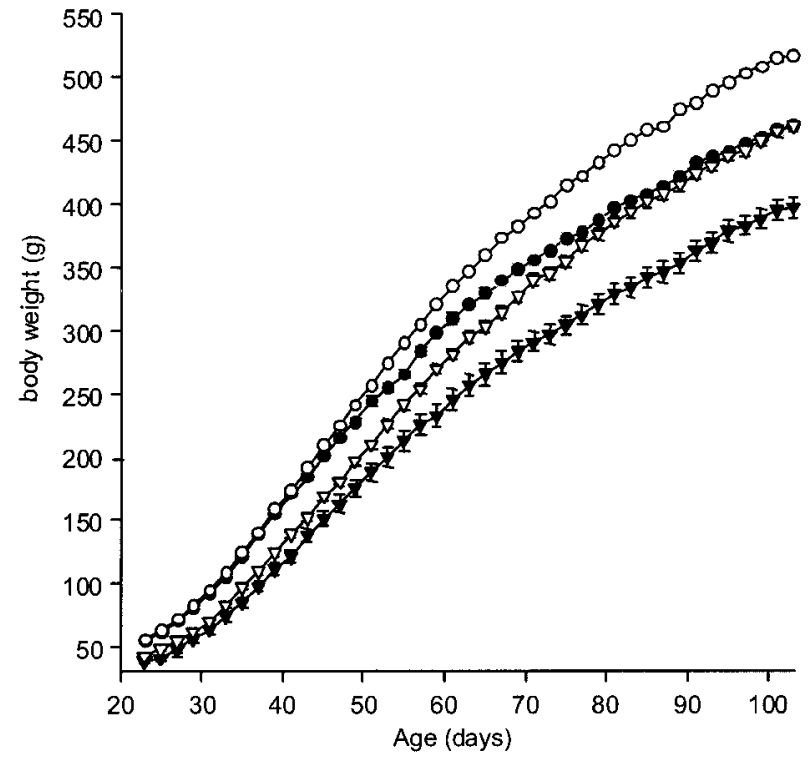

Figure 1 Postnatal growth curves of $A D$ and $U N$ offspring from weaning until commencement of $\mathrm{GH}$ treatment. $\mathrm{AD}$ control $(\mathbf{0})$, AD hypercaloric $(\bigcirc), \mathrm{UN}$ control $(\boldsymbol{\nabla})$ and $\mathrm{UN}$ hypercaloric $(\nabla)$. Data are means \pm S.E.M.; some error bars are too small to show.

reduction in SBP significantly $(P<0 \cdot 005)$ more pronounced in hypertensive UN animals on both control and hypercaloric nutrition (Fig. 3). The GH-induced fall in SBP occurred independently of diet. SBP in normotensive $\mathrm{AD}$ animals fed the control diet was unaltered by $\mathrm{GH}$ treatment.

\section{Food intake}

Caloric intake (calories consumed/g body weight per day) was significantly increased $(P<0 \cdot 001)$ in $\mathrm{AD}$ and $\mathrm{UN}$ animals fed the hypercaloric diet. UN animals were hyperphagic $(P<0 \cdot 0001)$ on both diets compared with AD animals. During the GH-treatment period caloric intake remained significantly $(P<0 \cdot 0001)$ increased in $\mathrm{AD}$ and UN animals fed hypercaloric nutrition (Fig. 4). Treatment with GH resulted in an overall significant $(P<0 \cdot 0005)$ increase in caloric intake in all treated animals although the $\mathrm{GH}$-induced increase in caloric intake was less marked in UN animals compared with AD animals (programming+ $\mathrm{GH}$ interaction $P<0 \cdot 05)$. However, in animals fed hypercaloric nutrition, the effect of GH treatment on food intake was significantly reduced in AD animals and was absent in $\mathrm{UN}$ animals (diet $+\mathrm{GH}$ interaction $P<0 \cdot 05$ ).

\section{Plasma hormone concentrations following GH treatment}

IGF-I plasma concentrations were significantly increased following treatment with GH (Fig. 5) and were not different between $\mathrm{AD}$ and $\mathrm{UN}$ offspring nor affected by postnatal hypercaloric nutrition. Maternal undernutrition 
Table 1 Body weight and tissue data following 21 days of treatment with GH. Data are means \pm S.E.M. and were analysed by three-way factorial ANOVA

\begin{tabular}{|c|c|c|c|c|c|c|c|}
\hline & $\begin{array}{l}\text { Body weight } \\
\text { (BW) (g) }\end{array}$ & $\begin{array}{l}\text { Heart } \\
(\% \mathrm{BW})\end{array}$ & $\begin{array}{l}\text { Liver } \\
\text { (\% BW) }\end{array}$ & $\begin{array}{l}\text { Kidneys } \\
\text { (\% BW) }\end{array}$ & $\begin{array}{l}\text { Spleen } \\
(\% \text { BW })\end{array}$ & $\begin{array}{l}\text { Adrenals } \\
(\% \mathrm{BW})\end{array}$ & $\begin{array}{l}\text { Nose-anus } \\
(\mathrm{mm})\end{array}$ \\
\hline \multicolumn{8}{|l|}{ Treatment } \\
\hline \multicolumn{8}{|l|}{ AD control diet } \\
\hline Saline & $453 \pm 17$ & $0.315 \pm 0.012$ & $2.911 \pm 0.05$ & $0 \cdot 786 \pm 0 \cdot 01$ & $0.191 \pm 0.006$ & $0.015 \pm 0.001$ & $246 \pm 5 \cdot 7$ \\
\hline $\mathrm{GH}$ & $548 \pm 16$ & $0.354 \pm 0.011$ & $3 \cdot 476 \pm 0.06$ & $0.796 \pm 0.02$ & $0 \cdot 279 \pm 0.016$ & $0.019 \pm 0.001$ & $269 \pm 2 \cdot 8$ \\
\hline \multicolumn{8}{|l|}{ AD hypercaloric diet } \\
\hline Saline & $532 \pm 13$ & $0.314 \pm 0.006$ & $2 \cdot 958 \pm 0 \cdot 14$ & $0.765 \pm 0.01$ & $0 \cdot 174 \pm 0.008$ & $0.014 \pm 0.001$ & $257 \pm 3 \cdot 4$ \\
\hline $\mathrm{GH}$ & $611 \pm 15$ & $0 \cdot 350 \pm 0 \cdot 011$ & $3 \cdot 692 \pm 0 \cdot 11$ & $0.736 \pm 0.02$ & $0 \cdot 315 \pm 0.029$ & $0 \cdot 018 \pm 0.001$ & $271 \pm 3.9$ \\
\hline \multicolumn{8}{|l|}{ UN control diet } \\
\hline Saline & $406 \pm 10$ & $0.309 \pm 0.005$ & $2 \cdot 928 \pm 0.07$ & $0.734 \pm 0.02$ & $0 \cdot 218 \pm 0 \cdot 012$ & $0.014 \pm 0.001$ & $234 \pm 2 \cdot 0$ \\
\hline $\mathrm{GH}$ & $487 \pm 21$ & $0.321 \pm 0.005$ & $3 \cdot 678 \pm 0.15$ & $0.753 \pm 0.01$ & $0 \cdot 278 \pm 0 \cdot 013$ & $0.020 \pm 0.001$ & $255 \pm 1 \cdot 8$ \\
\hline \multicolumn{8}{|l|}{ UN hypercaloric diet } \\
\hline Saline & $488 \pm 18$ & $0.310 \pm 0.009$ & $3.081 \pm 0.06$ & $0.707 \pm 0.02$ & $0 \cdot 180 \pm 0 \cdot 007$ & $0 \cdot 013 \pm 0 \cdot 001$ & $247 \pm 2 \cdot 8$ \\
\hline $\mathrm{GH}$ & $566 \pm 17$ & $0.335 \pm 0.006$ & $3 \cdot 625 \pm 0 \cdot 10$ & $0 \cdot 660 \pm 0 \cdot 01$ & $0 \cdot 271 \pm 0 \cdot 026$ & $0.017 \pm 0.001$ & $259 \pm 2 \cdot 6$ \\
\hline \multicolumn{8}{|l|}{ Effects } \\
\hline Programming effect & $P<0 \cdot 0001$ & $P<0.05$ & NS & $P<0.0005$ & NS & NS & $P<0.0001$ \\
\hline $\mathrm{GH}$ effect & $P<0.0001$ & $P<0.0001$ & $P<0.0001$ & NS & $P<0.0001$ & $P<0.0001$ & $P<0.0001$ \\
\hline Diet effect & $P<0.0001$ & NS & NS & $P<0.005$ & NS & $P<0.05$ & $P<0.005$ \\
\hline \multicolumn{8}{|l|}{ Interactions } \\
\hline Programming + diet & NS & NS & NS & NS & NS & NS & NS \\
\hline Programming $+\mathrm{GH}$ & NS & NS & NS & NS & NS & NS & NS \\
\hline Diet $+\mathrm{GH}$ & NS & NS & NS & NS $(P=0.08)$ & NS & NS & NS $(P=0.052$ \\
\hline Programming $+\operatorname{diet}+\mathrm{GH}$ & NS & NS & NS & NS & NS & NS & NS \\
\hline
\end{tabular}

NS, not significant.

resulted in offspring with significantly elevated fasting plasma insulin concentrations that were further amplified by hypercaloric nutrition. Treatment with GH significantly increased plasma insulin levels in all treated animals $(P<0 \cdot 05)$. A significant diet $+\mathrm{GH}$ interaction indicated that $\mathrm{GH}$ increased insulin concentrations to a greater extent in hypercalorically fed animals than in those fed the control diet (Fig. 5). Plasma leptin concentrations were

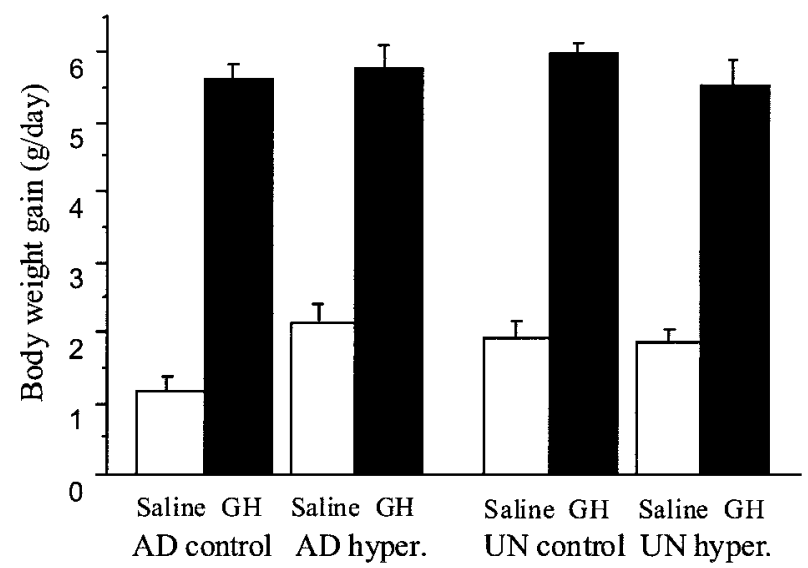

Figure 2 Body weight response in animals following $\mathrm{GH}$ treatment for 21 days. $P<0.0001$ for effect of $\mathrm{GH}$ treatment. There was no significant difference in growth response between $A D$ and $U N$ offspring or between control and hypercaloric (hyper.) diets. significantly elevated in UN offspring and were amplified in $\mathrm{AD}$ and UN offspring fed hypercalorically (Fig. 5). GH treatment had no effect on plasma leptin concentrations.

\section{Tissue data following GH treatment}

Retroperitoneal fat pad weight was significantly higher in UN offspring on both diets compared with AD offspring

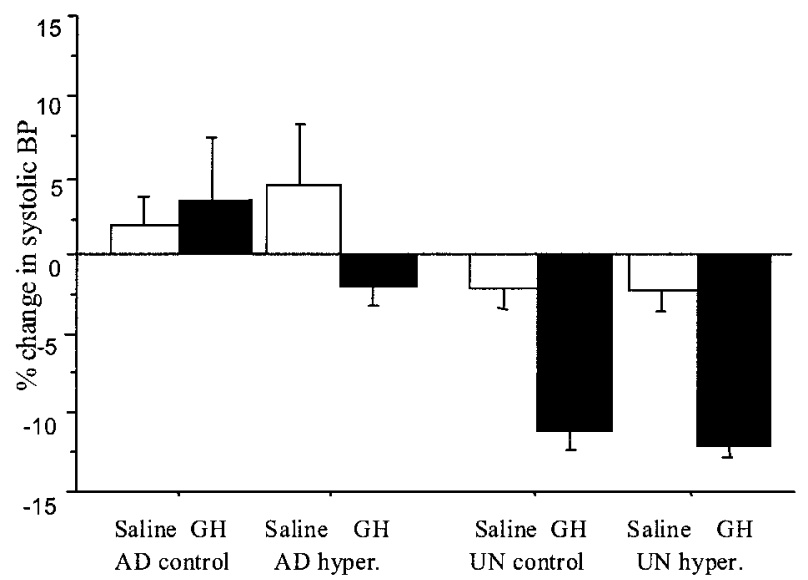

Figure 3 Change in SBP in $\mathrm{AD}$ and $\mathrm{UN}$ animals following $\mathrm{GH}$ treatment for 21 days. $P<0 \cdot 05$ for effect of $\mathrm{GH}$ treatment; programming $+\mathrm{GH}$ interaction $P<0 \cdot 005$. 


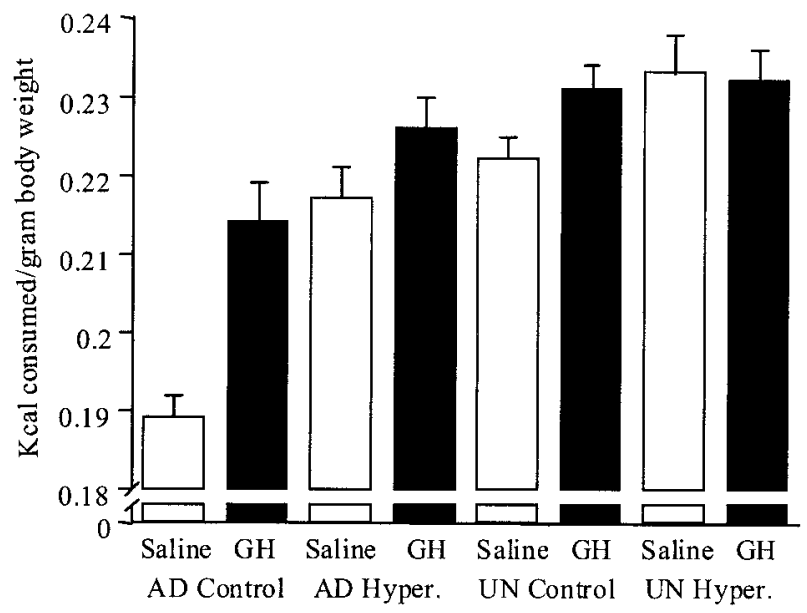

Figure 4 Food intake (kcal/g body weight per day) during 21 days of treatment with GH. $P<0.0001$ for effect of programming and hypercaloric diet; $P<0.0005$ for effect of $\mathrm{GH}$ treatment.

Interactions: programming $+\mathrm{GH}$ treatment $P<0 \cdot 05$; hypercaloric diet $+\mathrm{GH}$ treatment $P<0 \cdot 05$.

and was significantly amplified by hypercaloric nutrition. $\mathrm{GH}$ treatment significantly reduced fat mass in all treated animals and was more effective in reducing fat mass in $\mathrm{AD}$ and UN offspring fed hypercaloric nutrition postnatally. A highly significant programming $+\mathrm{GH}$ interaction indicated that GH treatment was more effective in reducing retroperitoneal fat pad mass in UN offspring on both diets compared with AD offspring (Fig. 6). Gonadal fat pad mass was significantly higher in UN offspring on both diets compared with AD offspring and was significantly amplified by hypercaloric nutrition. GH treatment reduced gonadal fat mass in all treated animals (Fig. 6). As observed with retroperitoneal fat, a diet $+\mathrm{GH}$ interaction was evident with GH treatment being more effective at reducing gonadal fat mass in $\mathrm{AD}$ and $\mathrm{UN}$ offspring fed hypercaloric nutrition.

UN offspring had significantly smaller hearts than AD offspring and heart size was not affected by hypercaloric nutrition. Treatment with GH significantly increased heart-to-body weight ratios in all treated animals (Table 1). UN offspring had significantly smaller kidneys than $\mathrm{AD}$ offspring and kidney-to-body ratios were reduced in hypercalorically fed animals. Treatment with GH had no effect on kidney size (Table 1). Adrenal size was not affected by fetal programming although hypercalorically fed animals had smaller adrenals relative to body weight than control fed animals. Treatment with GH significantly increased adrenal size in all GH-treated animals and adrenal size was reduced relative to body weight in hypercalorically fed animals (Table 1). Liver and spleen weights were not different between $\mathrm{AD}$ and $\mathrm{UN}$ animals. $\mathrm{GH}$ treatment significantly increased liver and spleen weights in all treated animals (Table 1).
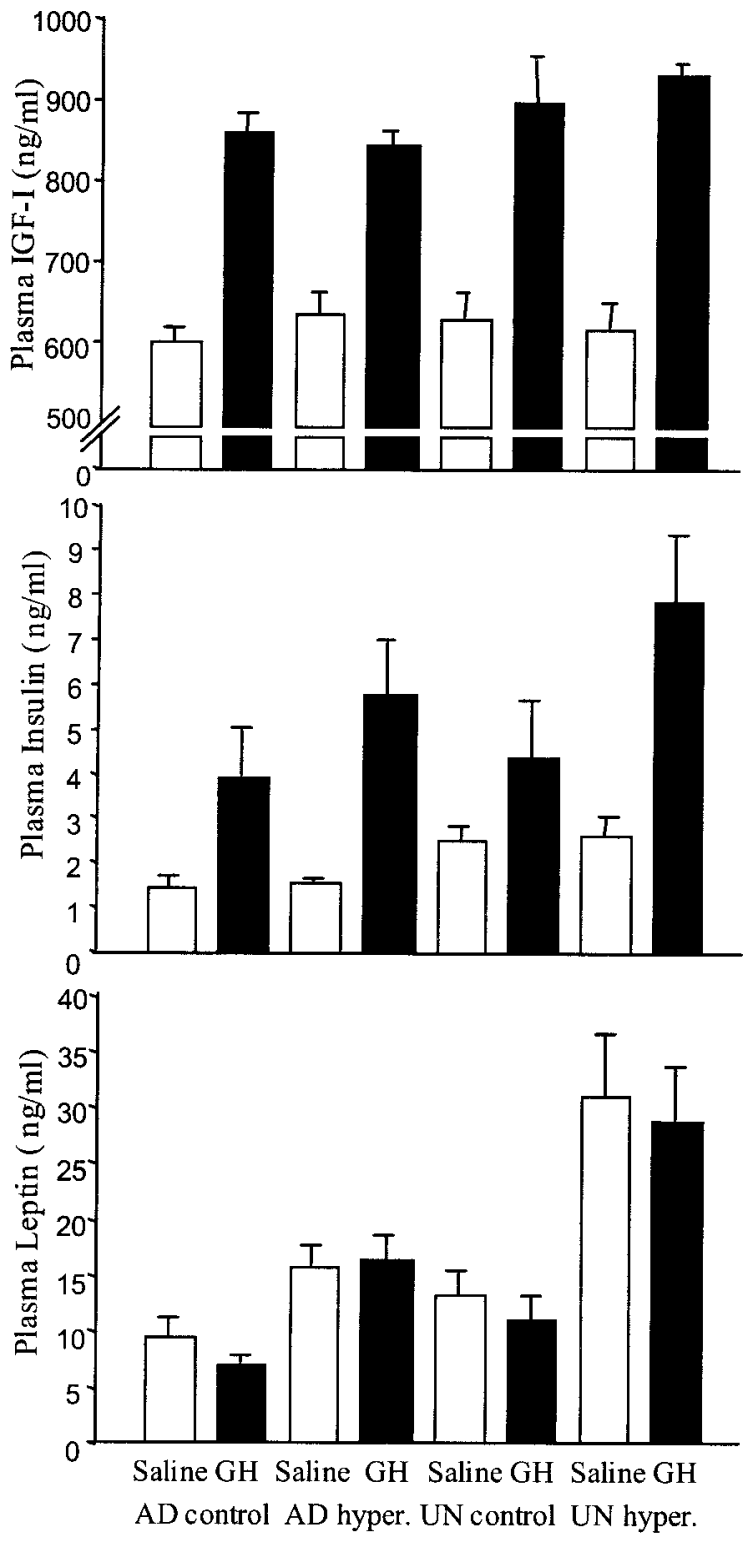

Figure 5 Fasting plasma IGF-I, insulin and leptin concentrations following treatment with $\mathrm{GH}$ for 21 days. Due to inequality of variance and non-normal distribution, insulin and leptin data were $\log _{10}$ transformed prior to analysis. IGF-I: $P<0.0001$ for effect of $\mathrm{GH}$ treatment; no interactions; insulin: $P<0.05$ for effect of programming, hypercaloric diet and $\mathrm{GH}$ treatment; diet $+\mathrm{GH}$ treatment interaction $P<0.05$; leptin: $P<0.0001$ for effect of programming and hypercaloric diet; no interactions.

\section{Blood biochemistry following GH treatment}

Fasting blood plasma glucose was not different between $\mathrm{AD}$ and $\mathrm{UN}$ offspring. Glucose concentrations were significantly increased by hypercaloric nutrition and amplified further following GH treatment (Table 2). Plasma urea concentrations were significantly decreased in 


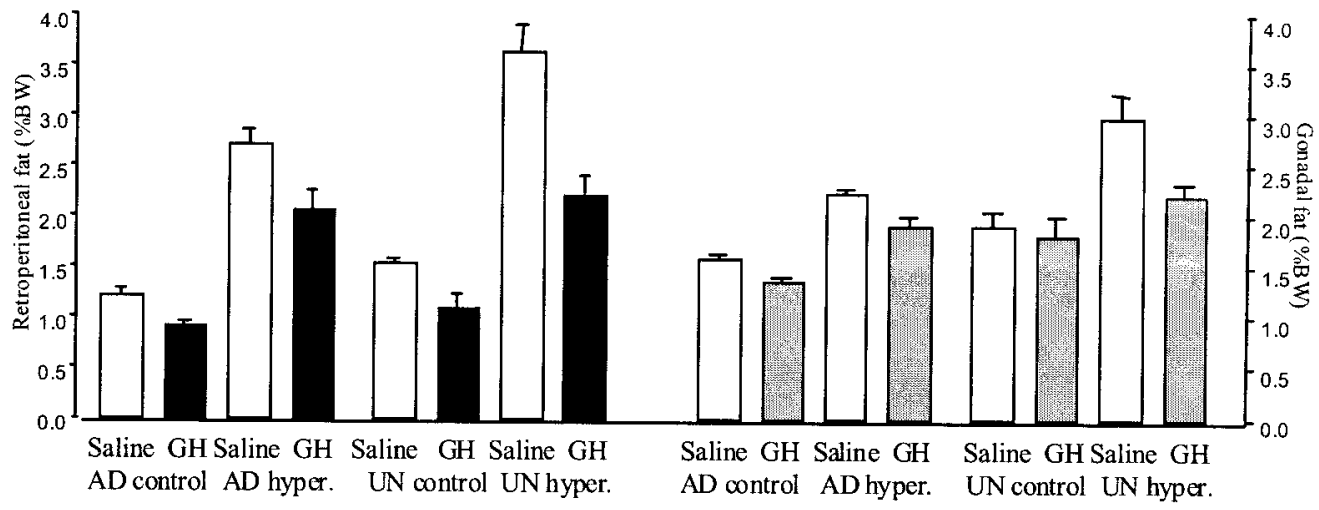

Figure 6 Retroperitoneal and gonadal fat pad weight (expressed as \% body weight (BW)) after 21 days of $\mathrm{GH}$ treatment. $P<0 \cdot 0005$ for effect of programming, hypercaloric diet and $\mathrm{GH}$ treatment. Interactions: retroperitoneal fat: programming $+\mathrm{GH}$ treatment $P<0 \cdot 05$, hypercaloric diet $+\mathrm{GH}$ treatment $P<0 \cdot 05$; gonadal fat: hypercaloric diet $+\mathrm{GH}$ treatment $P<0 \cdot 05$.

hypercalorically fed animals but there was no effect of programming or $\mathrm{GH}$ treatment. Creatinine levels were significantly increased with $\mathrm{GH}$ treatment. A programming $+\mathrm{GH}$ interaction was present with $\mathrm{GH}$ treatment, increasing creatinine more significantly in UN animals. Plasma creatinine was not affected by hypercaloric nutrition (Table 2).

Plasma albumin was significantly reduced in UN offspring compared with $\mathrm{AD}$ offspring and was increased following GH treatment in all groups. There was no effect of diet on plasma albumin concentrations (Table 2). Plasma potassium concentrations were not different between $A D$ and $U N$ offspring. GH treatment increased potassium in all treated groups and hypercaloric nutrition caused a reduction in plasma potassium. Plasma alanine aminotransferase (ALT) concentrations were significantly increased in hypercalorically fed animals but there was no effect of programming or $\mathrm{GH}$ treatment (Table 2). A

Table 2 Blood biochemistry data following 21 days of treatment with GH. Data are means \pm S.E.M. and were analysed by three-way factorial ANOVA

\begin{tabular}{|c|c|c|c|c|c|c|c|c|}
\hline & $\begin{array}{l}\text { Glucose } \\
(\mathrm{mmol} / \mathrm{l})\end{array}$ & $\begin{array}{l}\text { Urea } \\
(\mathrm{mmol} / \mathrm{l})\end{array}$ & $\begin{array}{l}\text { Creatinine } \\
(\mathrm{mmol} / \mathrm{l})\end{array}$ & $\begin{array}{l}\text { Albumin } \\
(\mathrm{g} / \mathrm{l})\end{array}$ & $\begin{array}{l}\text { Potassium } \\
(\mathrm{mmol} / \mathrm{l})\end{array}$ & $\begin{array}{l}\text { ALT } \\
(\mathrm{mmol} / \mathrm{l})\end{array}$ & $\begin{array}{l}\text { Sodium } \\
(\mathrm{mmol} / \mathrm{l})\end{array}$ & $\begin{array}{l}\text { Haematocrit } \\
(\%)\end{array}$ \\
\hline \multicolumn{9}{|l|}{ Treatment } \\
\hline \multicolumn{9}{|l|}{$\mathrm{AD}$ control diet } \\
\hline Saline & $7 \cdot 44 \pm 0 \cdot 2$ & $6 \cdot 22 \pm 0 \cdot 1$ & $0 \cdot 055 \pm 0 \cdot 01$ & $29 \cdot 2 \pm 0 \cdot 4$ & $8 \cdot 7 \pm 0 \cdot 4$ & $23 \cdot 7 \pm 2 \cdot 4$ & $134 \cdot 8 \pm 0 \cdot 3$ & $45 \cdot 6 \pm 0 \cdot 7$ \\
\hline $\mathrm{GH}$ & $8.59 \pm 0.5$ & $5 \cdot 89 \pm 0 \cdot 3$ & $0.057 \pm 0.01$ & $29 \cdot 7 \pm 0.6$ & $10 \cdot 6 \pm 0 \cdot 5$ & $28 \cdot 8 \pm 3 \cdot 1$ & $135 \cdot 0 \pm 0 \cdot 6$ & $43 \cdot 0 \pm 0 \cdot 6$ \\
\hline \multicolumn{9}{|l|}{ AD hypercaloric diet } \\
\hline Saline & $8.69 \pm 0.5$ & $4 \cdot 80 \pm 0 \cdot 2$ & $0 \cdot 054 \pm 0 \cdot 01$ & $27 \cdot 7 \pm 0 \cdot 5$ & $8 \cdot 1 \pm 0 \cdot 6$ & $38 \cdot 0 \pm 3 \cdot 8$ & $136 \cdot 0 \pm 0 \cdot 7$ & $47 \cdot 3 \pm 0 \cdot 4$ \\
\hline $\mathrm{GH}$ & $10 \cdot 44 \pm 0 \cdot 7$ & $5 \cdot 30 \pm 0 \cdot 2$ & $0.059 \pm 0.01$ & $28.9 \pm 0 \cdot 6$ & $8 \cdot 4 \pm 0 \cdot 5$ & $37 \cdot 0 \pm 3 \cdot 5$ & $137 \cdot 5 \pm 0 \cdot 5$ & $43 \cdot 6 \pm 0 \cdot 4$ \\
\hline \multicolumn{9}{|l|}{ UN control diet } \\
\hline Saline & $8 \cdot 43 \pm 0.3$ & $6 \cdot 64 \pm 0 \cdot 4$ & $0.055 \pm 0.01$ & $26 \cdot 4 \pm 0 \cdot 7$ & $9 \cdot 1 \pm 0 \cdot 8$ & $29 \cdot 8 \pm 2 \cdot 4$ & $134 \cdot 2 \pm 0 \cdot 5$ & $46 \cdot 7 \pm 0 \cdot 6$ \\
\hline $\mathrm{GH}$ & $9 \cdot 37 \pm 0 \cdot 7$ & $7 \cdot 35 \pm 0 \cdot 6$ & $0.068 \pm 0.01$ & $27 \cdot 7 \pm 0 \cdot 7$ & $10 \cdot 7 \pm 0 \cdot 6$ & $22 \cdot 0 \pm 4 \cdot 0$ & $134 \cdot 5 \pm 0 \cdot 9$ & $44 \cdot 0 \pm 0 \cdot 9$ \\
\hline \multicolumn{9}{|l|}{ UN hypercaloric diet } \\
\hline Saline & $8 \cdot 87 \pm 0.7$ & $5 \cdot 30 \pm 0 \cdot 4$ & $0.053 \pm 0.01$ & $26 \cdot 7 \pm 0 \cdot 3$ & $8 \cdot 2 \pm 0 \cdot 6$ & $40 \cdot 5 \pm 4 \cdot 1$ & $134 \cdot 1 \pm 1 \cdot 0$ & $46 \cdot 1 \pm 0 \cdot 4$ \\
\hline $\mathrm{GH}$ & $9 \cdot 48 \pm 0 \cdot 7$ & $5 \cdot 80 \pm 0 \cdot 4$ & $0.066 \pm 0.01$ & $28 \cdot 3 \pm 0 \cdot 6$ & $8 \cdot 6 \pm 0 \cdot 8$ & $27 \cdot 5 \pm 3 \cdot 1$ & $136 \cdot 2 \pm 0 \cdot 6$ & $43 \cdot 8 \pm 0 \cdot 3$ \\
\hline \multicolumn{9}{|l|}{ Effects } \\
\hline Programming effect & NS & NS & $P<0.05$ & $P<0 \cdot 005$ & NS & NS & $P<0.05$ & NS \\
\hline $\mathrm{GH}$ effect & $P<0 \cdot 05$ & NS & $P<0.0001$ & $P<0.005$ & $P<0 \cdot 05$ & NS & $P<0.05$ & $P<0.0001$ \\
\hline Diet effect & $P<0.05$ & $P<0.005$ & NS & NS & $P<0.005$ & $P<0.005$ & $P<0.05$ & NS \\
\hline \multicolumn{9}{|l|}{ Interactions } \\
\hline Programming + diet & NS & NS & NS & NS & NS & NS & NS & NS \\
\hline Programming $+\mathrm{GH}$ & NS & NS & $P<0.05$ & NS & NS & $P<0.05$ & NS & NS \\
\hline $\mathrm{Diet}+\mathrm{GH}$ & NS & NS & NS & NS & NS & NS & NS & NS \\
\hline Programming $+\operatorname{diet}+\mathrm{GH}$ & NS & NS & NS & NS & NS & NS & NS & NS \\
\hline
\end{tabular}

NS, not significant. 
programming $+\mathrm{GH}$ interaction indicated that $\mathrm{GH}$ reduced ALT levels in UN offspring on both diets but not in AD offspring. Plasma sodium was significantly lower in UN offspring and was increased in animals fed hypercaloric nutrition. GH increased plasma sodium levels in all treated groups. Blood haematocrit was significantly reduced in all GH-treated animals but was not affected by programming or hypercaloric diet.

\section{Discussion}

We have previously shown that an adverse prenatal environment induced by maternal undernutrition can result in hyperinsulinaemia, hyperleptinaemia, hyperphagia, hypertension and development of obesity in offspring during postnatal life (Vickers et al. 2000, 2001a). Furthermore, the pathogenesis is amplified by postnatal hypercaloric nutrition (Vickers et al. 2000). We have recently shown that IGF-I treatment can alleviate the hypertension induced by an adverse prenatal environment and/or diet-induced obesity (Vickers et al. 2001b). Since IGF-I is regulated by GH, we have investigated in the present study whether metabolic and cardiovascular disorders in this paradigm can be alleviated by GH therapy. Our results demonstrate that $\mathrm{GH}$ treatment can normalise blood pressure in animals that are hypertensive as a result of adverse prenatal influences or diet-induced obesity. The decrease in blood pressure is paralleled by a marked reduction in fat mass. However, treatment with $\mathrm{GH}$ resulted in a further increase in hyperinsulinaemia. Importantly, this study suggests a divergence between hypertension and hyperinsulinaemia; blood pressure was normalised in the setting of GH-exacerbated hyperinsulinaemia. These results suggest that $\mathrm{GH}$ treatment during adult life may attentuate hypertension indirectly via amelioration of obesity or more directly via GH-induced increases in IGF-I acting on the vasculature.

Central to both syndrome X and GHD are abdominal/ visceral obesity, insulin resistance and hypertension. The increased cardiovascular morbidity and mortality demonstrated in GHD adults suggests a close association between the two syndromes. However, until recently, GH and IGF-I were considered essential only to the control of linear growth and glucose homeostasis, and for the maintenance of skeletal muscle mass. However, a large body of evidence from animal and human studies has shown that the heart is a target for the GH-IGF-I axis (Sacca et al. 1994). In particular, studies on GHD adults have suggested that $\mathrm{GH}$ is essential for the maintenance of a normal cardiac structure and function, since these patients exhibit left ventricular hypertrophy and striking inotropic impairment, which is reversed by GH treatment (Merola et al. 1993, Cittadini et al. 1994). In the present study, GH treatment caused a significant reduction in blood pressure in animals that were hypertensive as a result of adverse prenatal influences. Importantly, SBP in normotensive animals was unaffected by $\mathrm{GH}$ treatment. GH treatment also resulted in a significant increase in relative heart size in all treated animals as reported by others (Cittadini et al. 1996, Isgaard et al. 1997). While these findings agree with those of others for a role for $\mathrm{GH}$ in improving cardiac function, this is the first report of GH acting as a potent antihypertensive agent via reduction of SBP.

Because early postnatal growth is GH and IGF-I dependent, failure of catch-up growth in children following exposure to an adverse prenatal environment has been attributed to alterations in somatotrophic axis regulation. However, while some studies report GHD and decreased plasma IGF-I concentrations (Woodall et al. 1996, Albertsson-Wikland et al. 1998), others report resistance to GH, IGF-I and/or insulin in the presence of normal GH, IGF-I and insulin profiles (Gluckman \& Harding 1997, Chatelain et al. 1998). Furthermore, it has been shown that $\mathrm{GH}$ secretion, either spontaneous or evoked, is blunted in obesity (Scacchi et al. 1999). It may be possible that an adverse prenatal environment leads to alterations in $\mathrm{GH}$ action which, amplified by chronic postnatal hypercaloric nutrition, may lead to a secondary GHD. However, in our study this would seem unlikely as there was no reduction in plasma IGF-I concentrations as a result of programming or hypercaloric nutrition. This fits with work by ourselves (Woodall et al. 1996) and others showing that postnatal alterations in GH secretion and IGF-I concentrations as a result of prenatal events are normalised at a young age (Muaku et al. 1996).

Replacement of GH in GHD adults results in a marked reduction of central obesity and significant reduction in total cholesterol but little change in other risk factors, in particular insulin resistance and dyslipidaemia (Hew et al. 1998). The marked effect of GH therapy on body composition has been a consistent observation in many studies (de Boer et al. 1995) and our observation of markedly reduced fat mass fits with the lipolytic effects of GH. Furthermore, our observations of marked reductions in body fat mass following $\mathrm{GH}$ therapy and the corresponding fall in SBP also concur with the well-established association between abdominal obesity and elevated blood pressure. However, as in GHD patients treated with GH, we observed a marked worsening of the diet-induced hyperinsulinaemia. Importantly, our study indicates a disassociation between insulin resistance and hypertension with GH treatment. Despite the marked worsening of the hyperinsulinaemia in UN offspring, there was a highly significant fall in SBP.

UN offspring were hyperphagic compared with $\mathrm{AD}$ animals on both diets prior to the onset of GH treatment. While rising plasma insulin levels are normally associated with decreasing appetite (Schwartz et al. 1992), the hyperinsulinaemia seen in the UN animals is likely to reflect insulin resistance or reduced insulin action, as seen in children born with intrauterine growth retardation (Hofman et al. 1997). Although GH treatment resulted in 
an overall increase in food intake, there was a lower response in the UN offspring, particularly in those animals fed hypercaloric nutrition. Although the effect of GH on food intake has been observed previously (Byatt et al. 1993), the mechanism underlying the differential response in appetite stimulation in UN animals warrants further investigation.

The fall in blood haematocrit and increased plasma sodium concentration in GH-treated animals concur with previous observations by others (Patel et al. 1978, Feld \& Hirschberg 1996). An increment in plasma volume after GH administration has been attributed to the well-known sodium-retaining effects of $\mathrm{GH}$, possibly mediated by a direct effect on the renal tubule. Alternatively, the GHIGF-I axis may also be an important link in mediating a structurally adaptive growth response in the blood vessel wall (Wickman et al. 1997).

The precise mechanisms underlying the induction of adult hypertension and obesity by an adverse fetal environment induced by maternal undernutrition are not fully understood. Nephron endowment at birth is inversely related to the risk of developing essential hypertension in later life (Mackenzie \& Brenner 1995, Mackenzie et al. 1996). We have observed significant reductions in glomeruli number in UN offspring (authors' unpublished observations) and this supports recent work by others showing that an adverse fetal environment can give rise to a reduction in nephron number (Hinchliffe et al. 1992, Merlet-Benichou et al. 1997). It is possible that the decrease in renal fat mass following $\mathrm{GH}$ treatment in the present study directly lowered blood pressure via a reduction in medullary compression as proposed by Hall et al. (1998). More recently, an adipose-derived reninangiotensin system has been described with angiotensinogen overproduction by adipose tissue resulting in elevated angiotensin II levels in the progression to obesity-related hypertension. We therefore speculate that GH treatment may indirectly lower blood pressure by ablation of fat mass concomitant with a down-regulation of the paracrine renin-angiotensin system. It is also tempting to speculate that GH treatment may lower blood pressure via IGF-Imediated down-regulation of the angiotensin II type 1 receptor as proposed in previous reports (Leri et al. 1999, Nilsson et al. 2000, Vickers et al. 2001b).

This study adds to the growing body of evidence supporting a beneficial role for GH in improving cardiovascular function and, in particular, in those adults who are hypertensive and obese as a consequence of adverse prenatal or postnatal environmental conditions. The mechanisms underlying the normalisation of blood pressure after $\mathrm{GH}$ treatment are still to be elucidated. A possible explanation which requires further investigation may relate to the profound vasodilatory effect of insulin and IGF-I which has been observed in vitro. Interestingly, this response has been shown to remain intact in patients with type 2 diabetes (Izhar et al. 2000).

\section{References}

Albertsson-Wikland K, Boguszewski M \& Karlberg J 1998 Children born small-for-gestational age: postnatal growth and hormonal status. Hormone Research 49 7-13.

Barker DJ 1995 The fetal and infant origins of disease. European Journal of Clinical Investigation 25 457-463.

Bengtsson B-A 1993 The consequences of growth hormone deficiency in adults. Acta Endocrinologica 128 2-5.

Bengtsson BA, Abs R, Bennmarker H, Monson JP, Feldt-Rasmussen U, Hernberg-Stahl E, Westberg B, Wilton P \& Wuster C 1999 The effects of treatment and the individual responsiveness to growth hormone $(\mathrm{GH})$ replacement therapy in $665 \mathrm{GH}$-deficient adults. KIMS Study Group and the KIMS International Board. Journal of Clinical Endocrinology and Metabolism 84 3929-3935.

de Boer H, Blok GJ \& Van der Veen EA 1995 Clinical aspects of growth hormone deficiency in adults. Endocrine Reviews 16 63-86.

Byatt JC, Staten NR, Salsgiver WJ, Kostelc JG \& Collier RJ 1993 Stimulation of food intake and weight gain in mature female rats by bovine prolactin and bovine growth hormone. American Journal of Physiology 264 E986-E992.

Caidahl K, Eden S \& Bengtsson B-A 1994 Cardiovascular and renal effects of growth hormone. Clinical Endocrinology 40 393-400.

Chatelain PG, Nicolino M, Claris O, Salle B \& Chaussain J 1998 Multiple hormone resistance in short children born with intrauterine growth retardation? Hormone Research 49 20-22.

Cittadini A, Cuocolo A, Merola B, Fazio S, Sabatini D, Nicolai E, Colao, Longobardi S, Lombardi G \& Sacca L 1994 Impaired cardiac performance in GH-deficient adults and its improvement after GH replacement. American Journal of Physiology 267 E219-E225.

Cittadini A, Stromer H, Katz SE, Clark R, Moses AC, Morgan JP \& Douglas PS 1996 Differential cardiac effects of growth hormone and insulin-like growth factor-1 in the rat. A combined in vivo and in vitro evaluation. Circulation 93 800-809.

Feld S \& Hirschberg R 1996 Growth hormone, the insulin-like growth factor system, and the kidney. Endocrine Reviews 17 423-480.

Gluckman PD \& Harding JE 1997 The physiology and pathophysiology of intrauterine growth retardation. Hormone Research 48 11-16.

Godfrey KM \& Barker DJP 2000 Fetal nutrition and adult disease. American Journal of Clinical Nutrition 1344s-1352s.

Hall JE, Brands MW, Henegar JR \& Shek EW 1998 Abnormal kidney function as a cause and a consequence of obesity hypertension. Clinical and Experimental Pharmacology and Physiology 25 58-64.

Hew FL, O’Neal D, Kamarudin N, Alford FP \& Best JD 1998 Growth hormone deficiency and cardiovascular risk. Bailliere's Best Practise and Research. Clinical Endocrinology and Metabolism 12 199-216.

Hinchliffe SA, Lynch MRJ, Sargent PH, Howard CV \& VanVelzen D 1992 The effect of intrauterine growth retardation on the development of renal nephrons. British Journal of Obstetrics and Gynaecology 99 296-301.

Hofman PL, Cutfield WS, Robinson EM, Bergman RN, Menon, RK, Sperling MA \& Gluckman PD 1997 Insulin resistance in short children with intrauterine growth retardation. Journal of Clinical Endocrinology and Metabolism 82 402-406.

Isgaard J, Kujacic V, Jennische E, Holmang A, Sun XY, Hedner T, Hjalmarson A \& Bengtsson BA 1997 Growth hormone improves cardiac function in rats with experimental myocardial infarction. European Journal of Clinical Investigation 27 517-525.

Izhar U, Hasdai D, Richardson DM, Cohen P \& Lerman A 2000 Insulin and insulin-like growth factor-I cause vasorelaxation in human vessels in vitro. Coronary Artery Disease 11 69-76.

Jackson AA, Langley-Evans SC \& McCarthy HD 1996 Nutritional influences in early life upon obesity and body proportions. Ciba Foundation Symposium 201 118-129. 
Johannsson G, Marin P, Lonn L, Ottosson M, Stenlof K, Bjorntorp P, Sjostrom L \& Bengtsson BA 1997 Growth hormone treatment of abdominally obese men reduces abdominal fat mass, improves glucose and lipoprotein metabolism, and reduces diastolic blood pressure. Journal of Clinical Endocrinology and Metabolism 82 727-734.

Leri A, Liu Y, Wang X, Kajstura J, Malhotra A \& Anversa P 1999 Overexpression of insulin-like growth factor-1 attenuates the myocyte renin-angiotensin system in transgenic mice. Circulation Research 84 752-762.

Lewis RM, Vickers MH, Batchelor DC, Bassett NS, Johnston BM \& Skinner SJM 1999 Effects of maternal captopril treatment on growth, blood glucose and plasma insulin in the fetal spontaneously hypertensive rat. Reproduction, Fertility and Development 11 403-408.

Mackenzie HS \& Brenner BM 1995 Fewer nephrons at birth: a missing link in the etiology of essential hypertension? American Journal of Kidney Disease 26 91-98.

Mackenzie HS, Lawler EV \& Brenner BM 1996 Congenital oligonephropathy: the fetal flaw in essential hypertension? Kidney International 55 (Suppl) S30-S34.

Merlet-Benichou C, Vilar J, Lelievre-Pegorier M, Moreau E \& Gilbert T 1997 Fetal nephron mass: its control and deficit. Advances in Nephrology from the Necker Hospital 26 19-45.

Merola B, Cittadini A, Colao A, Longobardi S, Fazio S, Sabatini D, Sacca L \& Lombardi G 1993 Cardiac structural and functional abnormalities in adult patients with growth hormone deficiency. Journal of Clinical Endocrinology and Metabolism 77 1658-1661.

Monson JP, Abs R, Bengtsson BA, Bennmarker H, Feldt-Rasmussen U, Hernberg-Stahl E, Thoren M, Westberg B, Wilton P \& Wuster C 2000 Growth hormone deficiency and replacement in elderly hypopituitary adults. KIMS Study Group and the KIMS International Board. Pharmacia and Upjohn International Metabolic Database. Clinical Endocrinology 53 281-289.

Muaku SM, Beauloye V, Thissen JP, Underwood LE, Fossion C, Gerard G, Ketelslegers JM \& Maiter D 1996 Long-term effects of gestational protein malnutrition on postnatal growth, insulin-like growth factor (IGF)-I, and IGF-binding proteins in rat progeny. Pediatric Research 39 649-655.

Nilsson ABM, Nitescu N, Chen Y, Guron GS, Marcussen N, Matejka GL \& Friberg P 2000 IGF-I treatment attenuates renal abnormalities induced by neonatal ACE inhibition. American Journal of Physiology 279 R1050-R1060.

Patel AJ, del Vecchio M \& Atkinson DJ 1978 Effect of undernutrition on the regional development of transmitter enzymes: glutamate decarboxylase and choline acetyltransferase. Developmental Neuroscience $141-53$.

Reaven GM 1993 Role of insulin resistance in human disease (syndrome X): an expanded definition. Annual Review of Medicine 44 121-131.

Reaven GM, Lithell H \& Landsberg L 1996 Hypertension and associated metabolic abnormalities - the role of insulin resistance and the sympathoadrenal system. The New England Journal of Medicine 334 374-381.
Reynolds RM \& Phillips DI 1998 Long-term consequences of intrauterine growth retardation. Hormone Research 49 (Suppl 2) $28-31$.

Sacca L \& Fazio S 1996 Cardiac performance: growth hormone enters the race. Nature Medicine 2 29-31.

Sacca Li, Cittadini A \& Fazio S 1994 Growth hormone and the heart. Endocrine Reviews 15 555-573.

Sas T, Mulder P \& Hokken-Koelega A 2000 Body composition, blood pressure, and lipid metabolism before and during long-term growth hormone $(\mathrm{GH})$ treatment in children with short stature born small for gestational age either with or without GH deficiency. Journal of Clinical Endocrinology and Metabolism 85 3786-3792.

Scacchi M, Pincelli AI \& Cavagnini F 1999 Growth hormone in obesity. International Journal of Obesity and Related Metabolic Disorders 23 260-271.

Schwartz MW, Figlewicz DP, Basler GA, Woods SC \& Porte D Jr 1992 Insulin in the brain: a hormonal regulator of energy balance. Endocrine Reviews 13 387-414.

Smith U, Axelsen M, Carvalho E, Eliasson B, Jansson PA \& Wesslau C 1999 Insulin signaling and action in fat cells: associations with insulin resistance and type 2 diabetes. Annals of the New York Academy of Sciences 892 119-126.

Vickers MH, Breier BH, Cutfield WS, Hofman PL \& Gluckman PD 2000 Fetal origins of hyperphagia, obesity and hypertension and its postnatal amplification by hypercaloric nutrition. American Journal of Physiology 279 E83-E87.

Vickers MH, Reddy S, Ikenasio BA \& Breier BH 2001a Dysregulation of the adipoinsular axis - a mechanism for the pathogenesis of hyperleptinemia and adipogenic diabetes induced by fetal programming. Journal of Endocrinology 170 323-332.

Vickers MH, Ikenasio BA \& Breier BH $2001 b$ IGF-1 treatment reduces hyperphagia, obesity, and hypertension in metabolic disorders induced by fetal programming. Endocrinology 142 3964-3973.

Wickman A, Friberg P, Adams MA, Matejka GL, Brantsing C, Guron G \& Isgaard J 1997 Induction of growth hormone receptor and insulin-like growth factor-I mRNA in aorta and caval vein during hemodynamic challenge. Hypertension 29 123-130.

Woodall SM, Breier BH, Johnston BM \& Gluckman PD 1996 A model of intrauterine growth retardation caused by chronic maternal undernutrition in the rat: effects on the somatotropic axis and postnatal growth. Journal of Endocrinology 150 $231-242$.

Received 2 August 2002 Accepted 13 August 2002 